\title{
AN EVALUATION OF THE 2013 CURRICULUM ASSISTANCE TRAINING PROGRAM FOR HISTORY TEACHERS IN PEKANBARU
}

\author{
Isjoni $^{1}$, M. Yogi Riantama ${ }^{2}$, Asyrul Fikri $^{3}$, Yuliantoro $^{4}$ \\ (isjoni@yahoo.com)
}

Faculty of Teachers Training and Education Universitas Riau, Indonesia.

\begin{abstract}
This study is aimed at measuring the effectiveness of the 2013 Curriculum implementation assistance training program for school principals and History teachers conducted by the education office in Pekanbaru City. The study was conducted using the CIPP (Context, Input, Process, and Product) evaluation model introduced by Stufflebeam (2003). The data were collected through interviews, documentation, and observation. The subject of the study was the Pekanbaru city education office. The results show that the evaluation of the 2013 Curriculum implementation assistance training program resulted in a background, goals, objectives, expected results, and legal basis; the Input Evaluation resulted in criteria for training participants, training preparation programs, companion criteria, training organizers, training facilities, mentoring strategies, mentoring patterns, mentoring training mechanisms, training manuals, training implementation schedules, and training funding; The process evaluation resulted in the implementation of mentoring preparation, program structure readiness, teaching material readiness, preparedness of assistant staff, readiness of organizers, and readiness of training facilities which became the foundation of the committee to carry out the training. Furthermore, the assistants carry out the learning process; Product evaluations produce training graduates' competency standards, the level of success of training participants, and the impact of training graduates. From the evaluation results, the context obtained a value of 4.96 in the Very Good category. While the process evaluation obtained an average of 2.6 Poor categories and product evaluations obtained a score of 2.80 Poor category. Overall, the evaluation component of the K13 mentoring training program for history subjects at the Pekanbaru City High School scores 3.7 in the Good category. This means that the implementation of the K13 mentoring training program for history subjects at the Pekanbaru City High School is at a good level.
\end{abstract}

Keywords: evaluation; 2013 Curriculum; training program 


\section{INTRODUCTION}

The implementation of the 2013 Curriculum implementation assistance training program is expected to have benefits for both schools and history teachers. However, the phenomena that occur in reality are different from what was expected. From the results of interviews by researchers with the Supervising Coordinator, Head of the Curriculum Section of High Schools, Heads of Plus High Schools, Heads of State Senior High Schools 11, Heads of High Schools 13, Heads of High Schools 1, and History Teachers, of the following problems are:

First, related to the material and method of its delivery, the history teacher training courses are theoretical-conceptual. Pieces of training are supposed to train the history teachers skills regarding the needs of their assignments. Second, the participant's problem. Some of the participants sent by some school to the training were not in accordance with the qualifications requested by the committee. For instance, the training was meant for history teachers, but those sent were geography, sociology teachers or of other subjects. Third, the training was not effective because the participants did not have a great curiosity. The participants were very passive in the class, not excited. Senior or elder history teachers usually lose enthusiasm, so they only listen. As a matter of fact, this type of training requires two or multi-way communication. With any other active learning strategies, this kind of the participant is usually difficult to advance.

In addition, the opportunity to join a training for history subject teachers is not evenly distributed. The training quota is not proportional to the number of history teachers. This was worsened by the absence of a culture of transmitting new knowledge to fellow history teachers at school. After training, history teachers do not take the initiative to share. Plus, there is no scheduled dissemination program from both the school and the Education Office as an opportunity to train fellow history teachers.

Another problem was the neglect of training evaluations. The training ends without evaluation. Even if there is an evaluation, the evaluation data are not used for future improvement. Evaluation is merely a formality. In fact, evaluation is supposed to find out the strengths and weaknesses of training for future improvements.

Based on the above mentioned phenomena, the researchers consider it important and necessary to conduct a research on the evaluation of the 2013 Curriculum implementation assistance training program for high schools in the Education Office of Pekanbaru by referring to the CIPP (Context, Input, Process, and Product) approach evaluation of context, input, process and results - developed by Stufflebeam (2003).

The study is expected to answer this research question: "To what extent is the evaluation of the 2013 Curriculum assistance training program implemented for history subjects at High School in Pekanbaru city" 
This study is specifically aimed at obtaining a clear description of the 2013 Curriculum implementation assistance program for history subjects in the city of Pekanbaru. Theoretically, this research is hoped to be beneficial for the development of the science of human resource management, especially the management of the quality of educator enhancement.

Practically, this research is expected to become an input for 1) Policymakers and education stakeholders in making decisions and implementing policies for improving the quality of educators; 2) Education Agency in managing and implementing quality improvement programs for educators; 3) Riau University in obtaining concrete information about the objective conditions of professional institutions in regions, particularly Pekanbaru city; 4) Educational institutions in developing and improving the quality of educators; 5) Educators in improving their professionalism in teaching and learning activities; 6) Researchers in developing ways of thinking critically, scientifically and applying a variety of professional institutional development thoughts at the operational practical level.

\section{Program Evaluation Concepts}

The implementation of a program always includes program evaluation activities. According to Stufflebeam, in Hashimoto (2010), program evaluation is a systematic collection of information about the activities, characteristics, and results of the program to make an assessment of the program, increase program effectiveness, and/ or inform decisions about future programs. Julie D. Hehnke (2007) in The State of Gifted Education in Nebraska, A Dissertation, The Graduate College at the University of Nebraska, defines evaluation as the systematic search and evaluation of information to provide feedback about an object in the form of programs, policies, technology, people, needs or activities.

Paul J. Gertler, et. al., (2011) states that an evaluation is a systematic and objective assessment of a project, program or policy being implemented or having been completed, either in the design, implementation, and results. In line with this, Stan, S Sangweni (2008) defines evaluation as a systematic and objective assessment of ongoing, completed projects, programs or policies on the design, implementation, and results of which aim to determine the relevance and achievement of the objectives, efficiency and effectiveness, impact, and sustainability. an evaluation is also related to the process of determining the value or significance of an activity, policy, or program. 
According to the International Federation of Red Cross and Red Crescent (2011), an evaluation is an objective and systematic evaluation of projects, programs, policies, planning, implementation, and results. An evaluation determines the suitability and objectives attainability, effectiveness, impacts, and sustainability. It provides useful information for decision making. Based on the description above, it can be concluded that the program evaluation is carried out to maintain the program implementation and ensure that the program is carried out on time, in accordance with the budget and targets. Typically, the intended target is related to outputs, i.e. goods or services produced by programs, policies, projects, or results.

\section{Program Evaluation Objectives}

Regarding to the program objectives, Anderson in Djudju Sudjana (2000) formulates evaluation objectives as follows: a) providing input for the program planning; b) presenting input to decision-makers relating to the following-up, expansion or termination of a program; c) providing input for decision-makers about program modifications or improvements; d) providing input regarding the supporting and inhibiting factors of the program; e) providing input for motivational and coaching activities (surveillance, supervision, and monitoring) for program organizers, managers and implementers; and f) presenting data about scientific foundation for evaluating educational programs.

\section{Concept of Education and Training}

According to Ivancevich (1995), training is more intended to help improve the ability of employees in carrying out current tasks. It is a systematic process to change employee work behavior in an effort to improve organization performance. It is related to skills and abilities to the work being carried out. In addition, Roger Buckley \& Jim Capled (2009) argue that education and training are a process of fostering understanding and knowledge of groups of facts, rules, and methods that are organized by prioritizing coaching, honesty, and skills.

Based on the description above, it can be concluded that education and training are inseparable entities in the world of employment. This is closely related since education and training are a series of systematic activities or processes aimed at increasing the knowledge, skills, and attitudes of an employee to carry out their jobs.

\section{RESEARCH METHODS}




\section{Research Design}

To provide information about this study, the research design is described as follows:

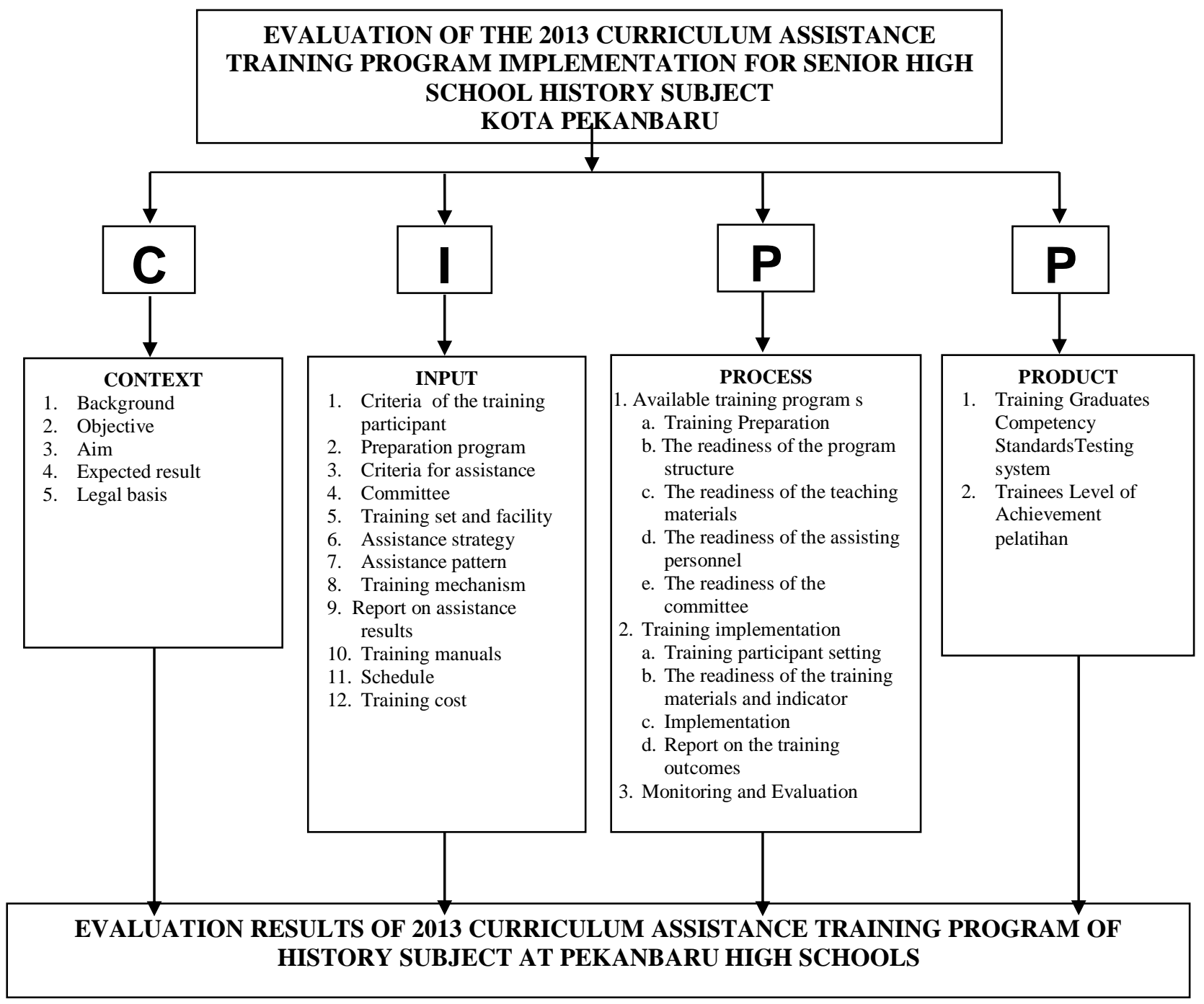

Figure 1. Model of Evaluation by Stufflebeam (2003)

Source of data is the main thing in research since it is the material to be studied. The researchers used in-depth interview and observation techniques to obtain the primary data and documentation studies to obtain secondary ones. In this study, the methods used in the data collection are interviews, documentation, and observation. The interviews were conducted to teachers who participated in the assistance training. Pieces of training documents were also taken as the source of the data. This includes training materials, training worksheets, and training evaluation documents. The observation was done by directly visiting and recording the activities in the classroom. Data from all these three methods of data collection were crosschecked before being analyzed.

The data analysis was using the Miles and Huberman technique in which data and information in the form of interviews and documentation studies, as well as 
observations about the implementation of the 2013 Curriculum assistance training program, are processed, and then presented descriptively and analyzed through; (a) data reduction; (b) data display; and (c) drawing/verification. The procedure can be described as follows:

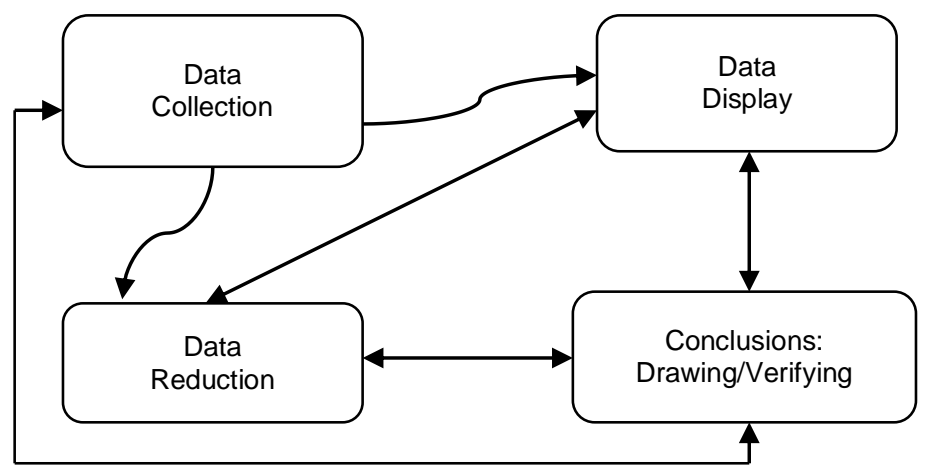

Sources: Miles, M. B. \& Huberman, A. M. (2014). Qualitative Data Analysis: A Sourcebook of New Methods California; SAGE publications Inc.

To improve the validity of the data, the researchers used a triangulation technique in which the data were gathered from different sources to collect similar data as the main data source. The data were gained from the Head of the Curriculum Section of the Education Department Pekanbaru; Chairperson and members of the Mentoring/Teaching Team of the 2013 Curriculum implementation training, supervisors, main principals, and the principals of the high schools where the history teachers work as the recipient of the program. The fundamental idea is that the phenomenon under study to be well understood so that a high level of truth is obtained when approached from various points of view. Capturing a single phenomenon from different points of view will allow a reliable level of truth.

\section{RESEARCH FINDINGS}

The findings show that the evaluation of the 2013 Curriculum assistance training program resulted in a background, goals, objectives, expected results, and legal basis; Input Evaluation resulted in criteria for training participants, training preparation programs, assistance criteria, training organizers, training facilities, training strategies, training patterns, training mechanisms, training manuals, training implementation schedules, and training funding; The process evaluation resulted in the implementation of mentoring preparation, readiness of program structure, readiness of teaching material, readiness of assistant staff, readiness of organizers, and readiness of training facilities which became the foundation of the committee to carry out the training. Furthermore, the assisting personnel carries out the learning process; Product Evaluations resulted in training graduates' competency standards, the level of success of training participants, 
and the impact of training graduates. From the evaluation results, the context obtained a value of 4.96 in the Very Good category. While the process evaluation is 2.6 in the Poor category and the product evaluation score is 2.80 in the Poor category. Overall, the evaluation components of the C-13 assistance training program for High School history subjects in Pekanbaru scores 3.7 in the Good category. This means that the implementation of the C-13 assistance training program for history subjects in Senior High Schools in Pekanbaru is at a good level.

\section{CONCLUSIONS}

The results of the context evaluation show that the context of the assistance training program scores 4.96 in the Very Good category. This can be seen from the subcomponents of the background, goals, objectives, expected results with a value of 5 , categorized Very Good and the legal aspect gets a value of 4.8, categorized Very Good. The evaluation results show that the $\mathrm{C}-13$ assistance training program input scores 3.6 Good, while Monitoring and Evaluation gets a score of 0, categorized Not Very Good. This means that the program input has not been fully met.

Based on the results of the process evaluation, it can be concluded that the implementation of the $\mathrm{C}-13$ assistance training program scores 2.6 in the Poor category. Moreover, the product component obtained a score of 2.8 with the category of Poor.

It is recommended that the implementation of the training can run well so that optimal goals can be achieved. Furthermore, it is suggested that the implementation of training be prepared in advance correctly, properly, and completely by drawing attention to the aspects of the Context, Input, Process, and Products so that the implementation of the training will be directed and measured and the assistance training program cannot be implemented impartially and is independent of the role of all stakeholders.

\section{REFERENCES}

Amriani Hamzah, (2013), Process and Focus of Training Needs Analysis, (online).

Education and Culture Human Resources Development Agency and Education Quality Assurance (2013) Ministry of Education and Culture 2013.

Pekanbaru City Education Office, (2014) Guidance on the Implementation of Teacher Assistants in the targeted history throughout Pekanbaru City. , (2014), Report on Cluster Assistance throughout Pekanbaru City Mapel.

, (2014), Final Accountability Report on the Use and Accountability of the 2013 Curriculum Assistance Block Grant; Parent Cluster SMA N 1 Pekanbaru City. 

2015.

(2015), Draft Strategic Plan for Pekanbaru City Education Agency 2010-

Ministry of Education and Culture, (2013), Guidelines for Assisting the Implementation of Curriculum 2013, Jakarta.

, (2013), Education and Culture Human Resources Development Agency and Education Quality Assurance, (2013), Guidelines for Assisting the Implementation of the 2013 Curriculum by the Core History Teacher, Pusbang Tendik, Jakarta.

, (2014), Technical Guidelines for Facilitating the Implementation of the 2013 Curriculum in High School in 2014, Directorate General of Elementary Education, Directorate of 2014 Middle School Development, Jakarta.

Julie D. Hehnke (2007) in Book: The State of Gifted Education in Nebraska, A Dissertation.

Miles, M. B. \& Huberman, A. M. (2014). Qualitative Data Analysis: A Sourcebook of New Methods California; SAGE publications Inc. 